С. С. Бадмаев, С. Ш. Сангадиев, М. В. Дармаев, Д. С. Сандитов. О модификации критерия стеклования сильновязких жидкостей

УДК 541.64:539.199:537.3

DOI 10.18101/2306-2363-2019-4-39-46

\title{
О МОДИФИКАЦИИ КРИТЕРИЯ СТЕКЛОВАНИЯ СИЛЬНОВЯЗКИХ ЖИДКОСТЕЙ
}

(C) Бадмаев С. C.

кандидат технических наук, доцент

кафедра общей физики

Бурятский государственный университет

670000, Улан-Удэ, ул. Смолина, 24а

E-mail: sayan75@mail.ru

(C) Сангадиев С. Ш.

кандидат физико-математических наук, доцент

Бурятский государственный университет

670000, Улан-Удэ, ул. Смолина, 24a

E-mail: sanser@mail.ru

\section{(C) Дармаев М. В.}

кандидат физико-математических наук, доцент, докторант

Бурятский государственный университет

670000, Улан-Удэ, ул. Смолина, 24а

E-mail: sanser@mail.ru

(C) Сандитов Д. С.

доктор физико-математических наук, профессор

кафедра общей физики

Бурятский государственный университет

670000, Улан-Удэ, ул. Смолина, 24а

E-mail: sanditov@bsu.ru

В рамках модели делокализованных атомов рассмотрена модификация критерия стеклования, предложенного ранее. Дается ее обоснование. Установлена линейная корреляция между энергией делокализации атома и температурой стеклования натриевогерманатных, щелочносиликатных и натриевоборатных стекол. В соответствии с критерием стеклования энергия делокализации атома линейно зависит от температуры стеклования, не проходящие через начало координат. Чтобы привести данный критерий в соответствие с экспериментом, введено в него эмпирическое слагаемое. Введение данного слагаемого качественно обосновано в рамках модели делокализованных атомов.

Ключевые слова: стеклование, делокализация атома, уравнение вязкости, неорганические стекла, энергия стеклования, сильновязкие жидкости, высокомолекулярные соединения

\section{Для цитирования:}

Бадмаев С. С., Сангадиев С. Ш., Дармаев М. В., Сандитов Д. С. О модификации критерия стеклования сильновязких жидкостей // Вестник Бурятского государственного университета. Химия. Физика. 2019. Вып 4. С. 39-46. 
В предыдущей работе [1] предложено следующее условие перехода жидкость - стекло

$$
\Delta \varepsilon_{e}=\frac{i}{2} k T_{g},
$$

где $i$ - число степеней свободы кинетической единицы, ответственной за стеклование, $k-$ постоянная Больцмана, $T_{\mathrm{g}}-$ температура перехода, $\Delta \varepsilon_{e}-$ энергия делокализации атома, равная работе по предельному упругому смещению атома из локального равновесного положения, совершаемой против внутреннего давления $p_{i}$, обусловленного силами межатомного (межмолекулярного) притяжения,

$$
\Delta \varepsilon_{e}=p_{i} \Delta \mathrm{v}_{e} .
$$

Здесь $\Delta \mathrm{v}_{e}$ - элементарный флуктуационный объем, необходимый для смещения атома (объем делокализации атома).

Критерий стеклования (1) основан на следующем представлении. Делокализация атома служит необходимым условием реализации элементарного акта вязкого течения стеклообразующих жидкостей (например, переключения межатомной связи [2]). Замораживание процесса делокализации атома в области стеклования [3] приводит к прекращению вязкого течения и к переходу расплава в стеклообразное состояние. Этот момент наступает тогда, когда энергия тепловых колебаний решетки, в расчете на атом, становится равной или меньше энергии делокализации атома [1].

Настоящее сообщение посвящено видоизменению критерия (1) и объяснению появления в нем дополнительного слагаемого.

\section{Линейная зависимость энергии делокализации атома от температуры стеклования}

Ранее было показано, что вывод уравнения Енкеля для вязкости [4] с привлечением модели делокализованных атомов дает возможность однозначно связать эмпирический параметр $D$ в этом уравнении с энергией делокализации атома $(k$ - постоянная Больцмана) $[3,5]$

$$
\Delta \varepsilon_{e}=k D .
$$

Из данных о вязкости [6] методом подгонки мы определили значения $D$ для различных неорганических стекол и проверили линейность зависимости $D$ от $T_{\mathrm{g}}$. Как и следовало ожидать на основе соотношений (1) и (3), у силикатных, германатных и боратных стекол параметр $D$ действительно линейно зависит от $T_{g}$, но описывается уравнением прямой (рис. 1 и 2), не проходящей через начало координат,

$$
D=a T_{g}+b .
$$

У натриевоборатных стекол с линейно - разветвленной структурой наклон прямой заметно больше $\left(a=\mathrm{d} D / \mathrm{d} T_{g} \approx 4.7\right)$ чем у натриевогерманатных ( $\left.a \approx 1.9\right)$ и щелочносиликатных $(a \approx 0.9)$ стекол с сеточной структурой. Постоянная $b \approx-$ $902 \mathrm{~K}$ у натриевоборатных стекол, наоборот, по величине существенно меньше, чем у германатных $(b \approx 1097 \mathrm{~K})$ и силикатных $(b \approx 1696 \mathrm{~K})$ стекол. Обращает внимание то обстоятельство, что у трех щелочносиликатных стекол экспериментальные точки ложатся практически на одну прямую (рис. 1). 


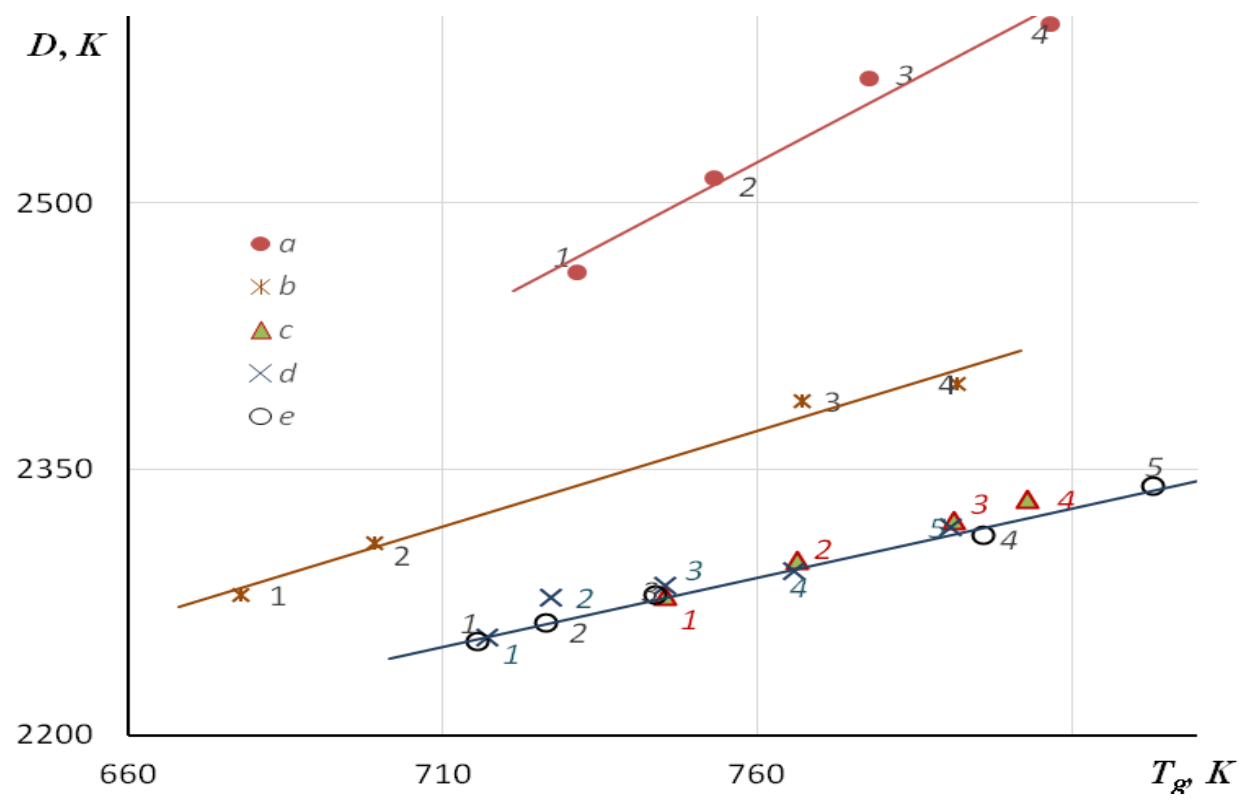

Рис. 1. Линейная корреляция между эмпирическим параметром уравнения Енкеля $D$ и температурой стеклования $T_{g}$ для двухкомпонентных силикатных и германатных стекол при различных содержаниях окислов: а $-\mathrm{GeO}_{2}-\mathrm{Na}_{2} \mathrm{O}$ (содержание $\mathrm{Na}_{2} \mathrm{O}$, мол. \%: 1 - 30, 2 - 25, 3 - 20, 4 - 15); b - $\mathrm{SiO}_{2}-\mathrm{PbO}$ (PbO, мол. \%: 1 - 50, 2 - 45, 3 - 30, 4 - 24,6); с $\mathrm{SiO}_{2}-\mathrm{K}_{2} \mathrm{O}\left(\mathrm{K}_{2} \mathrm{O}\right.$, мол. \%: $\left.1-25,2-20,3-15,4-13\right) ; \mathrm{d}-\mathrm{SiO}_{2}-\mathrm{Na}_{2} \mathrm{O}\left(\mathrm{Na}_{2} \mathrm{O}\right.$, мол. \%: $1-$ 33, $2-30,3-25,4-20,5-15)$; е $-\mathrm{SiO}_{2}-\mathrm{Li}_{2} \mathrm{O}$ ( $\mathrm{Li}_{2} \mathrm{O}$, мол. \%: $1-33,3,2-30,3-25,4$ $-14,5-10)$.

Таким образом, из соотношений (3) и (4) следует, что у исследованных стекол энергия делокализации атома $\Delta \varepsilon_{e}$ линейно зависит от температуры стеклования, однако прямые $\Delta \varepsilon_{e}-T_{g}$ не проходят через начало координат, что означает некоторое отклонение от условия перехода жидкость - стекло (1). В этих случаях критерий стеклования (1) можно привести в соответствие с экспериментом, если ввести в него эмпирическое слагаемое $\Delta \varepsilon_{0}$

$$
\Delta \varepsilon_{e}=\frac{i}{2} k T_{g}+\Delta \varepsilon_{0}
$$

физический смысл которого остается не совсем ясным. Рассмотрим один из возможных вариантов его качественной интерпретации. 


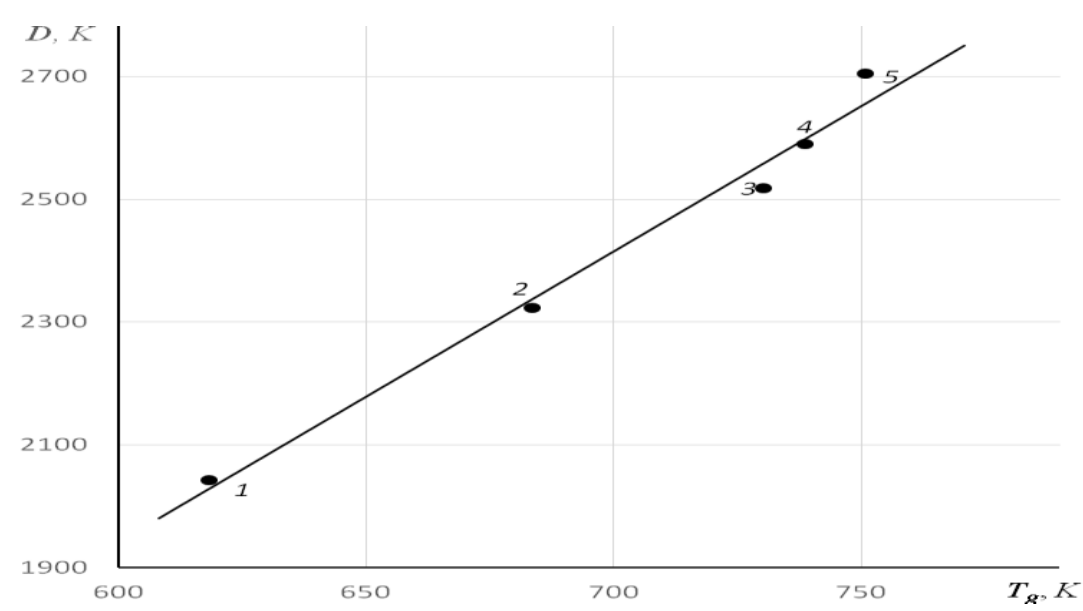

Рис. 2. Зависимость параметра уравнения Енкеля $D$ от температуры стеклования $T_{g}$ для натриевоборатных стекол $\mathrm{Na}_{2} \mathrm{O}-\mathrm{B}_{2} \mathrm{O}_{3}$ :

содержание $\mathrm{Na}_{2} \mathrm{O}$, мол.\%: $1-10,2-15,3-20,4-25,5-30$

\section{Обоснование уравнения (5)}

При более общем подходе необходимо учесть, что работа по делокализации атома совершается не только против внутреннего давления $p_{i}$, но и против внешнего давления $p$ [7] (например, атмосферного давления). Поэтому в равенстве (1) энергию $\Delta \varepsilon_{e}$ следует заменить энтальпией делокализации атома $\Delta H_{e}$

$$
\Delta H_{e}=\frac{i}{2} k T_{g},
$$

где $\Delta H_{e}$ определяется работой, совершаемой против внутреннего $p_{i}$ и внешнего $p$ давлений [7]

$$
\Delta H_{e}=\left(p_{i}+p\right) \Delta \mathrm{v}_{e}=\Delta \varepsilon_{e}+p \Delta \mathrm{v}_{e} .
$$

Условие стеклования (6) с учетом (7) преобразуется в равенство, совпадающее с соотношением (5),

$$
\Delta \varepsilon_{e}=\frac{i}{2} k T_{g}-p \Delta \mathrm{v}_{e},
$$

и эмпирическое слагаемое $\Delta \varepsilon_{e}$ оказывается связанным с работой, совершаемой против внешнего давления: $\Delta \varepsilon_{0}=-p \Delta \mathrm{v}_{e}$.

\section{О процессе стеклования. Обсуждение результатов}

Природа перехода аморфного вещества из жидкого в стеклообразное состояние остается одной из актуальных нерешенных проблем физики конденсированного состояния [3, 8-12]. 
С. С. Бадмаев, С. Ш. Сангадиев, М. В. Дармаев, Д. С. Сандитов. О модификации критерия стеклования сильновязких жидкостей

В качественном отношении стеклование практически всех аморфных веществ характеризуется общими закономерностями: зависимостью температуры стеклования от скорости охлаждения расплава, характерной своеобразной температурной зависимостью вязкости и времени релаксации в области стеклования, приближенным универсальным правилом Симхи - Бойера, а также «правилом двух третей» и т.д. [9-11]. Однако вместе с тем необходимо отметить, что для разных классов стекол при $T_{g}$ замораживается подвижность различных кинетических единиц, связанных с различным характером взаимодействий между частицами.

Стеклование линейных аморфных органических полимеров является процессом физической релаксации, связанным с потерей сегментальной подвижности при температуре стеклования [12], а стеклование неорганических стекол с сеточной структурой относится к процессам химической релаксации и обусловлено замораживанием процессов разрыва и рекомбинации валентных связей типа кремний-кислород-кремний $[12,13]$. Стеклование густосшитых сетчатых полимеров (например, эпоксидов) также имеет свою специфику [12], хотя в качественном отношении они подчиняются общим универсальным закономерностям стеклования, как и указанные выше стеклообразные системы.

Расчет энергии делокализации атома $\Delta \varepsilon_{e}$ с помощью формулы (4) из данных об эмпирическом параметре уравнения вязкости $D=2500$ [14] для силикатных стекол № 15 и № 18 (табл.) ( $R$ - газовая постоянная)

$$
\Delta \varepsilon_{e}=R D \approx 21 \text { кДж/моль }
$$

находится в согласии с результатами расчета $\Delta \varepsilon_{e}$ по формуле модели делокализованных атомов для этого же класса стекол [3, 7]: $\Delta \varepsilon_{\mathrm{e}} \approx 18-23$ кДж/моль. Обращает внимание то обстоятельство, что энергия делокализации атома $\Delta \varepsilon_{e}$, которая близка к энтальпии $\Delta H_{e}$ при $p_{i}>p$ [7], по порядку величины сравнима со средней энергией теплового колебательного движения решетки в области стеклования. Последняя, например, по закону равнораспределения энергии по степеням свободы (согласно классическому выражению $\varepsilon_{D}=3 N_{A} k T=3 R T$ ) для силикатных стекол, у которых $T_{g} \approx 700-900 \mathrm{~K}$, составляет около: $3 \mathrm{RTg} \approx 17-22$ кДж/моль..

У низкомолекулярных и высокомолекулярных органических стекол $(D=460$ $800 \mathrm{~K}$ ) величина $\Delta \varepsilon_{e}$ (табл.)

$$
\Delta \varepsilon_{e}=R D \approx 4-7 \text { кДж/моль }
$$

также близка к энергии теплового движения в области стеклования этих систем $\left(T_{g} \approx 200-300 \mathrm{~K}\right): 3 \mathrm{RT}_{\mathrm{g}} \approx 5-7$ кДж/моль, причем здесь энергия делокализации атома $\Delta \varepsilon_{e}$ по величине практически совпадает с высокотемпературным пределом свободной энергии активации вязкого течения $\Delta F_{\infty} \approx 5-10$ кДж/моль (табл.), которая вычисляется по данным о втором параметре $B$ уравнения Енкеля $[4,14]$ : $\Delta F_{\infty}=R B[3,5]$. Отсюда можно предположить, что в отличие от неорганических стекол вязкое течение и стеклование органических стекол и их расплавов тесно связано со сравнительно слабым межмолекулярным взаимодействием в этих системах. 
Таблица

Эмпирические постоянные уравнения Енкеля [4, 14] и вычисленные из них характеристики вязкого течения и стеклования аморфных веществ $\left(\Delta F_{\infty}=R B\right.$ и $\left.\Delta \varepsilon_{e}=R D\right)$

\begin{tabular}{|c|c|c|c|c|c|}
\hline \multirow{2}{*}{ Вещество } & $B$ & $D$ & $\Delta F_{\infty}$ & $\Delta \varepsilon_{e}$ & \multirow{2}{*}{ Литература } \\
\hline & \multicolumn{2}{|l|}{$\mathrm{K}$} & \multicolumn{2}{|c|}{ кДж/моль } & \\
\hline Силикатное стекло & & & & & \\
\hline №15 & 13226 & 2500 & 110 & 21 & [14] \\
\hline №18 & 13348 & 2500 & 111 & 21 & [14] \\
\hline $\mathrm{Na}_{2} \mathrm{O} 3 \mathrm{SiO}_{2}$ & - & 1840 & - & 15 & [4] \\
\hline Минеральное масло: & & & & & \\
\hline XII & 1195 & 800 & 10 & 7 & [14] \\
\hline XIII & 928 & 700 & 8 & 6 & [14] \\
\hline XIV & 741 & 600 & 6 & 5 & [14] \\
\hline$x V$ & 686 & 600 & 6 & 5 & [14] \\
\hline $\mathrm{XVI}$ & 615 & 600 & 5 & 5 & [14] \\
\hline Глицерин & - & 920 & - & 8 & {$[4]$} \\
\hline Полиизобутилен & - & 460 & - & 4 & [4] \\
\hline
\end{tabular}

$\Delta F_{\infty}$ - высокотемпературный предел свободной энергии активации вязкого течения стеклообразующих жидкостей $[5,16]$. Уравнение Енкеля: $\eta=A \exp [(\mathrm{B} / \mathrm{T})+$ $(\mathrm{C} / \mathrm{T}) \exp (\mathrm{D} / \mathrm{T})]$.

В неорганических силикатных стеклах свободная энергия активации вязкого течения $\Delta F_{\infty}=R B=110$ кДж/моль (табл.) рассматривается как потенциал переключения валентной химической связи [3]. Она заметно больше энергии делокализации атома $\Delta \varepsilon_{e}$. Элементарный акт вязкого течения этих стекол сводится к переключению валентной связи $[1,2,15]$. Необходимым условием переключения валентной связи Si-O, как мы считаем, служит делокализация мостикового атома кислорода в мостике $\mathrm{Si}-\mathrm{O}=-\mathrm{Si}$ [1]. Поэтому замораживание процесса делокализации мостикового атома в области стеклования приводит к прекращению вязкого течения и к переходу расплава неорганических стекол в стеклообразное состояние. Следовательно, у них переход жидкость-стекло лимитируется низкоактивационным процессом делокализации атома $[1,3,16]$.

В неорганических силикатных стеклах свободная энергия активации вязкого течения $\Delta F_{\infty}=R B=110$ кДж/моль (табл.) рассматривается как потенциал переключения валентной химической связи [3]. Она заметно больше энергии делокализации атома $\Delta \varepsilon_{e}$. Элементарный акт вязкого течения этих стекол сводится к переключению валентной связи [2, 15] [1]. Необходимым условием переключения валентной связи $\mathrm{Si}-\mathrm{O}$, как мы считаем, служит делокализация мостикового атома кислорода в мостике Si-O-Si [1]. Поэтому замораживание процесса делокализации мостикового атома в области стеклования приводит к прекращению вязкого течения и к переходу расплава неорганических стекол в стеклообразное состояние. Следовательно, у них переход жидкость-стекло лимитируется низкоактивационным процессом делокализации атома $[1,3,16]$. 
С. С. Бадмаев, С. Ш. Сангадиев, М. В. Дармаев, Д. С. Сандитов. О модификации критерия стеклования сильновязких жидкостей

\section{Заключение}

В соответствии с критерием стеклования (1) у германатных, боратных и силикатных стекол энергия делокализации атома $\Delta \varepsilon_{e}$ линейно зависит от температуры стеклования $T_{g}$. Однако прямые $\Delta \varepsilon_{e}-T_{g}$ не проходят через начало координат. Чтобы привести данный критерий в соответствие с экспериментом, введено в него эмпирическое слагаемое. Введение данного слагаемого качественно обосновано в рамках модели делокализованных атомов.

Работа выполнена при финансовой поддержке Министерства науки и высшего образования РФ (грант № 3.5406.2017/8.9).

\section{Литература}

1. Сандитов Д. С., Бадмаев С. С. Стеклование жидкости и замороженная деформация стекол // Неорганические материалы. - 2019. - Т. 55, № 10. - С. 1108-1115.

2. Мюллер Р. Л. Химические особенности полимерных стеклообразующих веществ и природа стеклообразования // В кн.: Стеклообразное состояние. Тр. III Всес. совещ. - М.-Л.: Изд-во АН СССР, 1959. - С. 61-71.

3. Sanditov D. S., Ojovan M. I. On Relaxation Nature of Glass Transition in Amorphous Materials // Physica B. - 2017. - V. 523. - P. 96-113.

4. Jenckel E. Zur temperaturabhängigkeit der Viskosität Von Schmelzen // Z. Physik. Chem. - 1939. — Bd. 184, № 1. — S. 309-319.

5. Сандитов Д. С. Модель вязкого течения стеклообразующих жидкостей и стекол // ДАН. - 2013. — Т. 451, № 6. - С. 650-654.

6. MDL ${ }^{\circledR}$ SciGlass - 7.8. Institute of Theoretical Chemistry, Shrewsbury, MA, 2012. www.sciglass.info.

7. Сандитов Д. С. Модель делокализованных атомов в физике стеклообразного состояния // ЖЭТФ. - 2012. - Т. 142, Вып. 1 (7). — С. 123-137.

8. Тропин Т. В., Шмельцер Ю. В., Аксенов В. Л. Современные аспекты кинетической теории стеклования // Успехи физических наук. — 2016. - Т. 186, № 1. - С. 47-73.

9. Сандитов Д. С., Бартенев Г. М. Физические свойства неупорядоченных структур. - Новосибирск: Наука, 1982. - 256 с.

10. Ростиашвили В. Г., Иржак В. И., Розенберг Б. А. Стеклование полимеров. - Л.: Химия, 1987. - 197 с.

11. Мазурин О. В. Стеклование. - Л.: Наука, 1986. - 158 с.

12. Бартенев Г. М., Бартенева А. Г. Релаксационные свойства полимеров. - М.: Химия, 1992. - 383 с.

13. Бартенев Г. М., Сандитов Д. С. Релаксационные процессы в стеклообразных системах. - Новосибирск: Наука, 1986. - 256 с.

14. Meerlender G. Die erweiterte Jenckel-Gleichung, eine leistungsfähige Viskositäts temperature - formel. I, II // Rheol. Acta. - 1967. — Bd. 6, № 4. - S. 309-377.

15. Мюллер Р. Л. Валентная теория вязкости и текучесть в критической области температур для тугоплавких стеклообразующих веществ // Ж. прикладной химии. 1955. — Т. 28, № 10. — С. 1077-1087.

16. Сандитов Д. С., Ожован М. И. Релаксационные аспекты перехода жидкость стекло // Успехи физ. наук. — 2019. — Т. 189, № 2. - С. 113-133. 


\section{ABOUT GLASS TRANSITION CRITERION MODIFICATIONS OF HIGHLY VISCOUS LIQUIDS}

Badmaev S. S.

Candidate of Engineering Sciences

Department of General Physics

Buryat State University

670000, Ulan-Ude, Smolina Str., 24a

E-mail: sayan75@mail.ru

Sangadiev S. Sh.

Candidate of Physics and Mathematics Sciences, associate Professor

Department of General Physics

Buryat State University

670000, Ulan-Ude, Smolina Str., 24a

Darmaev M. V.

Candidate of Engineering Sciences

Department of General Physics

Buryat State University

670000, Ulan-Ude, Smolina Str., 24a

E-mail: darmaev@bsu.ru

Sanditov D. S.

Doctor of Physical and Mathematical Sciences, Professor

Department of General Physics

Buryat State University

670000, Ulan-Ude, Smolina str., 24a

E-mail: sanditov@bsu.ru

In the framework of the model of delocalized atoms, a modification of the glass transition criterion proposed earlier is considered. Its justification is given. A linear correlation was established between the energy of atom delocalization and the glass transition temperature of sodium-germanate, alkali-silicate and sodium-borate glasses. According to the glass transition criterion, the delocalization energy of an atom is linearly dependent on the glass transition temperature not passing through the origin. In order to bring this criterion into line with the experiment, an empirical term is introduced into it. The introduction of this term is qualitatively justified in the framework of the model of delocalized atoms.

Keywords: glass transition, atom delocalization, viscosity equation, inorganic glasses, glass transition energy, highly viscous liquids, high molecular weight compounds 